\title{
Lectores y formación de ciudadanías en México. Observaciones sobre el Programa Nacional Salas de Lectura del Conaculta
}

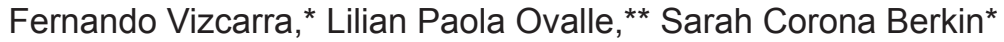

\section{Resumen}

Este artículo presenta un panorama sobre el estado actual de las Salas de Lectura en México. Proviene de un diagnóstico realizado por el Centro de Investigaciones Culturales-Museo de la Universidad Autónoma de Baja California, durante el año 2009, a petición del Consejo Nacional para la Cultura y la Artes (Conaculta). El objetivo primordial fue elaborar un ejercicio de identificación, caracterización y análisis de ciertos aspectos constitutivos de las Salas de Lectura en el país, a fin de establecer planes y estrategias de desarrollo cultural más eficaces. Es decir, quiénes son los promotores de lectura en México, dónde se localizan, en qué condiciones realizan sus labores y cuáles son sus experiencias en este ámbito. El presente texto se centra en la problemática de los mediadores de salas, los usuarios y los contextos en los que se desenvuelven dichos actores.

Palabras clave: Salas de Lectura, Conaculta, mediadores, usuarios.

\begin{abstract}
This article presents an overview on the current state of the Reading Rooms in Mexico. It comes from a diagnosis made by the Centre for Cultural Research-Museum of the Autonomous University of Baja California, during the year 2009, at the request of the National Council for Culture and the Arts (Conaculta). The primary objective was to develop an exercise for the identification, characterization and analysis of certain constituent aspects of the Reading Rooms in the country, in order to establish more effective cultural development strategies and plans. That is, who are the promoters of reading in Mexico, where are located, what are conditions engaged in their work and what are their experiences in this area. The text focuses on the problem of the mediators of rooms, users, and the contexts in which these actors operate.
\end{abstract}

Keywords: Rooms of Reading, Conaculta, mediators, users.

* Doctor en Sociología por la Universidad de Zaragoza, España. Es profesor-investigador del Instituto de Investigaciones Culturales-Museo de la Universidad Autónoma de Baja California, México. Correo electrónico: fernandovizcarra@hotmail.com.

** Doctora en Estudios del Desarrollo Global por la Universidad Autónoma de Baja California, México. Es investigadora del Instituto de Investigaciones Culturales-Museo de la Universidad Autónoma de Baja California. Correo electrónico: ovalle13@hotmail.com.

* Doctora en Comunicación por la Universidad Católica de Lovaina, Bélgica. Es investigadora titular de la Universidad de Guadalajara. Miembro del Sistema Nacional de Investigadores y de la Academia Mexicana de Ciencias. Correo electrónico: saco99@prodigy.net.mx. 


\section{Introducción}

El Programa Nacional Salas de Lectura (PNSL) fue creado por el Consejo Nacional para la Cultura y las Artes (Conaculta) en 1995, con el propósito de impulsar iniciativas ciudadanas orientadas a la promoción de la lectura. Actualmente existen más de 3300 Salas de Lectura en todo México, atendidas por diversos ciudadanos interesados en compartir la cultura del libro. El programa funciona a través de un esquema simple y, a la vez, muy exigente: los ciudadanos ponen el lugar, reúnen a sus lectores, organizan las sesiones y gestionan recursos para las actividades de sus salas. Aportan su saber, vitalidad y vocación sin remuneración alguna. El Conaculta, por su parte, contribuye con un fondo inicial de 100 libros, que se incrementa de acuerdo con la continuidad y crecimiento de cada sala. Además, asesora a los representantes de cada entidad (denominados "enlaces estatales") adscritos a sus respectivas instituciones culturales. Asimismo, organiza de manera permanente encuentros nacionales con promotores de lectura, que incluyen conferencias, talleres de capacitación, presentaciones de libros, etcétera. Todo esto se realiza en coordinación con los institutos y las secretarías de cultura de los estados. El programa está en marcha. Sin embargo, a más de 15 años de haberse creado, poco se sabe sobre el perfil de los responsables de cada sala (llamados "mediadores"), los usuarios, las estrategias de promoción de la lectura, los alcances y las repercusiones que ha tenido este quehacer en las comunidades.

Este artículo es parte de un diagnóstico más amplio sobre el estado actual de las Salas de Lectura en México, realizado para el Conaculta durante el año 2009 y coordinado por el Centro de Investigaciones Culturales-Museo de la Universidad Autónoma de Baja California.

El principal propósito fue elaborar un ejercicio de identificación, caracterización y análisis de la situación de las Salas de Lectura en el país, a fin de establecer planes y estrategias de desarrollo cultural más eficaces. De este modo, las preguntas que guiaron este diagnóstico fueron: quiénes son los mediadores de salas, qué perfiles tienen los usuarios y bajo qué condiciones se llevan a cabo las actividades de fomento a la lectura.

La evaluación contempló dos etapas de ejecución que al mismo tiempo se propusieron como dos estrategias metodológicas complementarias: un acercamiento estadístico, por un lado, y un registro de carácter cualitativo, 
por otro. La primera etapa consistió en la aplicación de una encuesta nacional a las Salas de Lectura abiertas y activas, cuyo propósito fue conocer estadísticamente la composición y el funcionamiento de dichos espacios. ${ }^{1}$

Se obtuvo un registro de carácter cuantitativo, descriptivo y exploratorio sobre las características generales y el desempeño de estos sitios de lectura. Para tal fin, se diseñaron dos encuestas, una para los mediadores (responsables de cada sala) y otra para los enlaces estatales (gestores del programa en cada entidad, adscritos a los institutos o secretarías de cultura). La primera encuesta se aplicó a 955 mediadores de Salas de Lectura que actualmente se encuentran en funcionamiento. Las categorías de análisis desarrolladas para esta encuesta fueron: 1) identificación del mediador, 2) condiciones físicas de las Salas de Lectura, 3) funcionamiento, 4) acervos y 5) usuarios. La segunda encuesta se asignó a 21 enlaces estatales con el propósito de identificar rasgos y características en la configuración de este ámbito institucional. Las categorías fueron: 1) perfil de los enlaces estatales, 2) gestión y 3) capacitación.

La segunda etapa de este estudio, de tipo cualitativo, comprendió la recuperación de la experiencia de los mediadores a través de entrevistas a profundidad y de un amplio registro fotográfico. En esta fase se recuperó la experiencia de los mediadores en torno a las labores cotidianas de las Salas de Lectura. Comprendió un ejercicio de memoria e interpretación, así como la observación de las prácticas grupales alrededor de estos espacios. El objetivo fue identificar los sentidos que nutren y orientan el funcionamiento de las Salas de Lectura, su permanencia y desarrollo, pero también sus retos y dificultades.

Durante los meses de mayo, junio y julio de 2009, los nueve investigadores $^{2}$ adscritos a este proyecto desarrollaron trabajo de campo en 22

1 La encuesta nacional se aplicó a 955 mediadores de un total de 3324 Salas de Lectura abiertas y activas, y el propósito fue conocer estadísticamente la composición y el funcionamiento actual de dichos espacios. La muestra representa el 28.7\% del universo. Tiene un margen de error de $2.5 \%$, con un nivel de confianza del $98 \%$, bajo el supuesto de muestreo aleatorio simple. Asimismo se aplicó una encuesta directa a 22 enlaces estatales, con el propósito de identificar rasgos y características en la configuración de este ámbito institucional. El cuestionario se aplicó entre los meses de mayo y agosto de 2009. 2 Participaron en este estudio: Lilian Paola Ovalle, investigadora de la Universidad Autónoma de Baja California; Sarah Corona Berkin, investigadora de la Universidad de 
entidades del país y visitaron 49 Salas de Lectura. Con las entrevistas a profundidad (registros de memoria y valoración) y los ejercicios de etnografía visual (registro fotográfico y análisis de las prácticas grupales) se obtuvo una representación estructural de los sentidos y las prácticas socioculturales vinculadas a la vida y funcionamiento de estos nichos de lectura. A través de las fotografías se analizó el inventario cultural, es decir, las características físicas de los espacios, el tipo de objetos y la relación entre ellos. De esta manera nos aproximamos al mediador, a sus prácticas y a las formas de armonizar su vida con la Sala de Lectura. Se examinaron los espacios y los objetos, los patrones de hospitalidad y ciertas prácticas de promoción de la lectura. Con respecto a los usuarios, se analizó en las fotografías aquello que nos permitiera comprender las formas de operar de las salas y las interacciones entre los usuarios y el mediador. Por su parte, la entrevista a profundidad se diseñó en torno a tres ejes temáticos:

1. Salas de Lectura y mediadores. Testimonios relacionados con las trayectorias de vida de los mediadores. Su relación con los libros y con el fomento de la lectura. Significados y relaciones de sentido en torno a las actividades de la Sala de Lectura. Perfiles del mediador ideal.

2. Salas de Lectura y gestión. Información relacionada con la organización y funcionamiento de las Salas de Lectura y con las tareas cotidianas de los mediadores. Capacitación y actualización de los mediadores. Representaciones sobre las instituciones culturales y los programas dedicados al fomento de la lectura (estados y federación). Experiencias exitosas de gestión. Dificultades, retos y obstáculos para el funcionamiento de dichos espacios.

Guadalajara; Dolores González Casanova, reconocida promotora y fundadora de programas de fomento a la lectura; Carmen Ruiz Nakasone, Rigoberto González y Jesús Arriaga Morales, académicos de la Universidad Pedagógica Nacional campus Ciudad de México; el sociólogo Rubén Pérez-Buendía; Julieta López Zamora, académica de la Universidad Autónoma de Baja California, y Fernando Vizcarra, como coordinador del proyecto de evaluación. A este equipo se sumó el respaldo institucional de Laura Athié, entonces directora adjunta de la Dirección General de Publicaciones del Conaculta, y de Socorro Venegas, coordinadora del Programa Nacional Salas de Lectura, así como de su valioso equipo de trabajo. 
3. Salas de Lectura y comunidades. Argumentaciones sobre los vínculos entre usuarios, lecturas y vida cotidiana. Valoraciones sobre el impacto de las Salas de Lectura en la comunidad. Experiencias del mediador en relación con su entorno social.

A partir de cada entrevista con el mediador de la Sala de Lectura, seleccionamos los enunciados más significativos con referencia a los ejes temáticos ya mencionados. El nivel de análisis se situó en el discurso (la oralidad y la imagen fotográfica) y en la observación de las actividades grupales desarrolladas en las Salas de Lectura.

Como ya mencionamos, por limitaciones de espacio este texto recoge una parte del diagnóstico total, aquella que aborda el perfil de los mediadores (quiénes son, a qué se dedican, cuáles son sus motivaciones y experiencias), algunos datos sobre la ubicación de las Salas de Lectura y, sobre todo, testimonios sobre el ámbito de los usuarios y las comunidades (percepciones sobre el efecto comunitario de las Salas de Lectura, experiencias de desarrollo cultural, lectura y formación de ciudadanías).

\section{¿Quiénes son los responsables de las Salas de Lectura?}

Nuestros encuestados son hombres y mujeres que, desde distintas regiones del país, trabajan de manera voluntaria promoviendo el acercamiento de sus comunidades a los libros. En el cuadro 1 se observa el resumen de las características sociodemográficas de los mediadores encuestados. El promedio de edad de los mediadores es de 42 años, tanto para hombres como para mujeres. De ellos, $36.1 \%$ son hombres y $63.9 \%$ mujeres. Es decir, en México, las Salas de Lectura están impulsadas en su mayoría por mujeres. Con respecto a la escolaridad, se observa que $52.9 \%$ de los mediadores cuenta con estudios de licenciatura y $14.3 \%$ realizó estudios de posgrado. En suma, $67.2 \%$ de los entrevistados tienen educación superior. Del resto, $10.8 \%$ concluyó una carrera técnica, $12.2 \%$ terminó la preparatoria, $7.3 \%$ acabó la secundaria y $2.6 \%$ cuenta sólo con la primaria o una escolaridad menor. Destaca en estos datos el alto nivel escolar de los mediadores, que sugiere una mayor relación de estos agentes con las diversas ofertas culturales e informativas -en particular con la cultura impresa- frente a los ciudadanos de menor escolaridad. Sin embargo, no podríamos afirmar que en México la 
educación superior garantiza la formación de lectores asiduos o de consumidores culturales frecuentes.

\section{Cuadro 1. Datos sociodemográficos de mediadores de salas de lectura (2009)}

\begin{tabular}{|c|c|c|}
\hline \multicolumn{3}{|c|}{$N=955$} \\
\hline Sexo & $\mathrm{n}$ & $\%$ \\
\hline Hombres & 342 & $36.1 \%$ \\
\hline Mujeres & 606 & $63.9 \%$ \\
\hline Total & 948 & $100 \%$ \\
\hline Escolaridad & $n$ & $\%$ \\
\hline Primaria & 24 & $2.6 \%$ \\
\hline Secundaria & 68 & $7.3 \%$ \\
\hline Preparatoria & 113 & $12.2 \%$ \\
\hline Técnica & 100 & $10.8 \%$ \\
\hline Licenciatura & 492 & $52.9 \%$ \\
\hline Posgrado & 133 & $14.3 \%$ \\
\hline Total & 930 & $100 \%$ \\
\hline Ocupación actual & $\mathrm{n}$ & $\%$ \\
\hline Profesor activo & 274 & $31.7 \%$ \\
\hline Empleado & 193 & $22.3 \%$ \\
\hline Bibliotecario & 98 & $11.3 \%$ \\
\hline $\begin{array}{l}\text { Profesionista } \\
\text { independiente }\end{array}$ & 74 & $8.6 \%$ \\
\hline Ama de casa & 45 & $5.2 \%$ \\
\hline Estudiante & 42 & $4.9 \%$ \\
\hline Comerciante & 28 & $3.2 \%$ \\
\hline Maestro jubilado & 19 & $2.2 \%$ \\
\hline Otro & 71 & $10.6 \%$ \\
\hline Total & 293 & $100 \%$ \\
\hline
\end{tabular}

Fuente: Conaculta, PNSL. 
Una variable determinante en el desempeño de los mediadores y en la proyección de sus Salas de Lectura son sus vínculos, más o menos estrechos, con las ofertas culturales en general, y con la lectura en particular. Estos vínculos se establecen a partir de la infancia y la juventud, desde los espacios de la familia o la escuela, según el papel de los padres, los abuelos y los maestros, y desde los distintos lugares geográficos y sociales donde se inscriben. Por ejemplo, Atzimba Mondragón Galindo, quien coordina una Sala de Lectura en Guadalajara, Jalisco, nos dice:

Mi papá es un lector. El contagio es el factor principal. Mi papá nos compraba muchos libros de niños. En una ocasión que viajó a Cuba nos trajo libros para niños y me los leía. Como profesora siempre platico con los alumnos de los libros. Le invierto tiempo porque me gusta. Yo disfruto la lectura, pasarle la lectura al otro. Somos (los de la Sala de Lectura) un grupo cohesionado, un grupo identificador, sabemos quiénes somos, pertenecemos a un lugar. La lectura no redime a nadie, pero la lectura sí nos hace mirar de modo distinto para animarnos a opinar. Estudié letras [maestría] [...] la historia de la literatura, me gusta la lectura, los libros.

Por su parte, Alfonso Carballo Hernández, integrante del Grupo Na' Naruni Nabanii (que significa "manos creadoras" en zapoteco) y mediador de una Sala de Lectura en Salina Cruz, Oaxaca, nos confiesa:

Provengo de una familia protestante. Mi abuelo fue pastor protestante. Mi madre nos leía la Biblia. El Cantar de los Cantares, Isaías. En la preparatoria conocí a un compañero llamado Roberto Carlos Díaz, le gustaba la poesía, me encantaban sus poemas. Decidí dedicarme a la literatura, a leer libros, a recopilar las revistas de la región, cualquier revistita. Así llegué a la literatura. Me gusta la poesía de César Vallejo. Me encantan las lenguas indígenas, aunque actualmente estoy leyendo a Paul Bowles, El cielo protector. La influencia fue más de mis compañeros. Una maestra de la secundaria me regaló una caja de libros que abrí hasta la preparatoria, descubrí así a los poetas del renacimiento hispánico.

En términos de ocupación (cuadro 1), resulta interesante que 31.7\% de los encuestados reporta ser profesor activo, 22.3\% afirma ser empleado y $11.3 \%$ es bibliotecario. Estos porcentajes contrastan con los de aquellos 
mediadores que afirman ser profesionistas independientes (8.6\%), amas de casa $(5.2 \%)$, estudiantes $(4.9 \%)$, comerciantes $(3.2 \%)$ y maestros jubilados $(2.2 \%)$. Parece significativo que, en suma, $45.2 \%$ de los mediadores encuestados sean profesores activos, bibliotecarios y maestros jubilados, o sea, actores vinculados con el sector educativo. Por una parte, estos datos pueden revelarnos la existencia de un grupo insatisfecho con las dinámicas de la escuela tradicional. Y por otro lado, pueden sugerir el predominio de una visión muy escolarizada de las Salas de Lectura. Es decir, la concepción de la Sala de Lectura como un lugar para enseñar a leer, o en su variante, complementar las labores pedagógicas. Al respecto, María Guadalupe Espinosa Pascual, responsable de la Sala de Lectura "La magia de los libros", ubicada en San Lucas Tecoplico, Tlaxcala, nos comenta:

La escuela fue mi única alternativa para acercarme a la literatura. Ya siendo maestra, descubrí el placer que me producía leer. Comencé, entonces, a resarcirme leyendo los materiales incluidos en los libros de texto gratuitos para la primaria, de la SEP. Este encuentro con la literatura me comenzó a mostrar que el mundo se podía ver de otra manera. Convencida de que leer cambiaba a la gente, decidí hacer mi mejor esfuerzo para que los niños le encontraran el gusto. Así que a partir de entonces, y hasta que me jubilé hace cinco años, todos los días, al comenzar la jornada de trabajo con el grupo, yo me tomaba diez minutos para leerles en voz alta cuentos a mis alumnos.

Desde su Sala de Lectura llamada "Una ventana al horizonte", en la ciudad de Aguascalientes, Amelia González también nos dice:

Soy docente de preescolar. Yo escuchaba eso de las salas y las salas y preguntaba con qué se come. Pero luego escuchaba a los compañeros de las salas diciendo que los culpables de que la gente no lea somos los maestros. Entonces, fue así como que me hirieron el orgullo. Yo empecé a trabajar la sala, pero nunca vi su dimensión. Alguien me decía: este libro me gustó, y yo pensaba: esas son cosas románticas de la lectura.

En un grupo de mediadores, identificamos que la promoción de la lectura está relacionada con un proyecto (o por lo menos con ciertas tentativas) de profesionalización. Al margen de aquellos mediadores que ya trabajan en 
escuelas y bibliotecas, o bien son profesores jubilados, muchos de éstos enlazan las actividades de la Sala de Lectura con la oferta de talleres de capacitación para diversas instituciones o grupos de la sociedad. Establecen agendas de servicios de capacitación cultural o de animación de eventos infantiles. Organizan en las fiestas infantiles sesiones de cuenta cuentos, teatro guiñol y representaciones diversas. Por supuesto, son los mediadores más jóvenes y algunos de ellos todavía se encuentran estudiando.

Cuadro 2. Experiencias previas en promoción de la lectura o animación cultural de los mediadores

\begin{tabular}{|l|c|c|}
\hline \multicolumn{3}{|c|}{$\mathbf{N}=955$} \\
\hline Sí & $\mathrm{n}$ & $\%$ \\
\hline No & 582 & $63.9 \%$ \\
\hline Total & 328 & $36.0 \%$ \\
\hline
\end{tabular}

Fuente: Conaculta, PNSL.

Cuando preguntamos a los encuestados sobre sus experiencias anteriores con respecto a la promoción de la lectura o la animación cultural (cuadro 2), encontramos que seis de cada 10 reportan tener experiencias previas en este ámbito. Sin embargo, se observa que $36 \%$ reconoció que sus primeras labores de promoción de la lectura se realizaron gracias al PNSL. De modo que, en muchos casos, las Salas de Lectura han significado el aprovechamiento de recursos humanos con experiencia en este rubro, y en otros, dichas salas se han sumado a proyectos culturales preestablecidos.

Sobre esto, Vivianne Thirion, responsable de la Sala de Lectura "El Juglar”, en la ciudad de México, señala:

Había participado en el diseño del programa y quería saber cómo funcionaba una Sala de Lectura en la práctica. Llevar a la práctica mis propias recomendaciones. Me tocó capacitar a los coordinadores. Hablé con el dueño de la librería El Juglar y llegamos a un acuerdo, me prestaron el espacio y desde 1996 abro la sala todos los jueves a las 5:30 p.m., rara vez terminamos a las 7.30, casi siempre nos alargamos. Tengo la credencial número 6 de Salas de Lectura. Cuando no 
puedo venir he mandado a alguna persona a sustituirme, pero no es igual, así que procuro venir todos los jueves. Me gusta mi sala, podría heredarla o cerrarla después de tanto tiempo, pero la disfruto. No es fácil, implica una disciplina.

También se suman a la configuración del PNSL las historias de quienes inician su relación con los libros. Desde el rancho El Chicalote, en Aguascalientes, el señor Cruz Olivares Sánchez, de la Sala de Lectura "El Cactus", nos cuenta:

Soy campesino. Una vez yendo en el centro de la ciudad, me encontré un cartel que decía "Leer para qué", me acerqué de pura curiosidad, preguntando para qué era eso, y me aceptaron. Me dio pauta para seguir, porque yo no tuve estudio. En las reuniones de Salas de Lectura me gustaron los comentarios que hacían hacia cada lectura, de los personajes y me fui interesando; hasta me metí a la escuela a terminar mi primaria. Yo no tenía estudios, verdad, pero yo leía mucho, si no leía mucho, vamos a decir, pedía mi libro y estaba yo leyendo, porque sí tuve hasta poquita escuela, un año de escuela yo creo. Tenía yo muchos libros que por aquí andan, tengo colecciones. Hablamos de treinta años de Mecánica Popular, de Selecciones, que fue con lo que me fui iniciando en la lectura y en las cosas que yo hago. Sí leía, pero nada más esporádicamente, a partir de que entré a esos cursos, me gustó y me acerqué a una escuela y ahorita, pues bendito sea Dios, estoy en la preparatoria. Todo esto lo estoy haciendo por la Sala de Lectura y por los chicos que veo que están demasiado adelantados para mí, y yo necesito estar casi al nivel. Para mí pararme en una biblioteca o ver los libros, de chico, para mí eso era imposible, vamos a decir, porque los libros estaban tan altos que para mí era imposible que me fueran a prestar un libro sin requisitos, sin ser conocido, ser huérfano, no tener ni credenciales ni nada. Ahorita yo voy a cualquier parte y me pueden prestar uno o lo compro, pero de chico, ¿quién me respaldaba a mí para que yo pidiera un libro?

Ahora bien, al indagar sobre las motivaciones de los encuestados para integrarse al Programa Nacional Salas de Lectura como mediadores (cuadro 3), se observó que el principal impulso para estos voluntarios fue el deseo de compartir la lectura con otros (47\%). Tres de cada 10 encuestados afirma que el motivo que los orienta a abrir su sala es la intención de promover la educación y la cultura. También se encontró que $10 \%$ se vio motivado 
por la ausencia de bibliotecas en su comunidad, $6 \%$ por su deseo de enseñar a leer a miembros de la comunidad y $2.7 \%$ de los encuestados reporta otros motivos. Estos datos refuerzan nuestra hipótesis de una percepción muy escolarizada de las Salas de Lectura, entendidas como extensiones del aula.

\section{Cuadro 3. Motivaciones de los encuestados para integrarse al Programa Nacional Salas de Lectura (2009)}

\begin{tabular}{|l|r|r|}
\hline \multicolumn{2}{|c|}{ N=955 } & \multicolumn{1}{|c|}{} \\
\hline & $\mathrm{n}$ & $\%$ \\
\hline Deseo de compartir la lectura con otros & 434 & $47 \%$ \\
\hline Promover la educación y la cultura & 316 & $34.3 \%$ \\
\hline Ausencia de bibliotecas en la comunidad & 92 & $10 \%$ \\
\hline Deseo de enseñar a leer a la comunidad & 55 & $6 \%$ \\
\hline Otro motivo & 25 & $2.7 \%$ \\
\hline Total & 922 & $100 \%$ \\
\hline
\end{tabular}

Fuente: Conaculta, PNSL.

No obstante, encontramos algunos mediadores que identifican los procesos de lectura con un tipo de desarrollo humano no necesariamente instrumental. Como Eduardo Aguirre, responsable de la Sala de Lectura "Carlos Monsiváis", en la ciudad de México:

Sólo sé que nos podemos conocer, nos podemos familiarizar en torno a un libro. La parte central de lo que es el sentido de vivir en sociedad, son los intercambios sociales. Así como que somos los apóstoles del fomento a la lectura, pues no. Esas son palabrerías, la cuestión es ver que realmente estamos haciendo algo por la lectura, y hacer algo por la lectura es no circunscribirnos a la lectura. Que la lectura no se convierta en un fin, sino en un medio.

Con desniveles de argumentación, existe entre los mediadores el convencimiento de que el desarrollo cultural de las personas, a través de la práctica frecuente de la lectura, permitirá mejorar sus condiciones de vida. Más aún, aquellos mediadores que trabajan con grupos vulnerables tienden a construir con mayor énfasis una concepción de la lectura relacionada con 
la transformación de los sujetos. Existe la certeza de que a través de la lectura, las personas pueden vivir de manera distinta e incidir en la construcción de relaciones sociales menos violentas o destructivas. Sin embargo, más allá de la necesidad de que el mediador sea un lector asiduo y un interlocutor en su comunidad, se hace necesario que participe también como un actor en la formación de ciudadanías. Se extiende la noción, pues, de que el libro y la lectura no son fines, sino medios para formar ciudadanos activos y organizados. La lectura no sólo como experiencia estética, sino también como práctica política. Una visión que también comparte Bernardina Hidalgo Comonfort, quien atiende la Sala de Lectura "Chunca", en Manzanillo, Colima:

El leer y el saber de la lectura es muy importante, porque cuando no entiendes algo no lo sabemos explicar. Hay mucha gente que mejor prende la tele. Leer es aprender [...] me gustaría que la gente lo tomara [el libro] y viera el significado de las palabras [...] que [entienda] el derecho como ciudadano. Defenderse cuando te lleguen a gritar a tu casa [...] que sepa qué dice la Constitución Política.

Igualmente, María Nieves Moreno Jacobo, de la Sala de Lectura "La alegría de compartir”, ubicada en El Rincón, Jalisco, nos explica:

[Leer] sirve para despertarnos, porque a través de la lectura crecemos. Las personas de antes no leían, pero tenían mucha imaginación. Pero ahorita, en la actualidad, el que no lee se va a quedar, el que no lee no va a crecer, el que no lee no va a aprender, el que no lee no se va a defender. Si uno no lee, por eso nos barren y nos trapean. Si lee, no necesita abogado, no ocupamos un abogado para defendernos.

A través de las Salas de Lectura, los mediadores emprenden una labor mediante la cual pueden valorarse a sí mismos y frente a su comunidad. Alrededor de estos espacios, y de acuerdo al grado de compromiso de cada mediador, se fortalecen los sentidos de solidaridad y de servicio a la comunidad. Al respecto, Juan Correa, de la Sala de Lectura "Despertar al saber", situada en Mérida, Yucatán, nos dice: "Mis experiencias exitosas ocurren cuando los niños de preescolar comienzan a leer, cuando comparten por vez primera 
sus lecturas, eso es muy gratificante. Cuando les leo un libro, se convierte en el libro más solicitado de la sesión o de la semana, para préstamo”.

En el mismo sentido se expresa Norma Elisa Álvarez Sánchez, de la Sala de Lectura “Ayacapixtlán”, en Yecapixtla, Morelos:

Pues sí, para mí es bien importante mi sala, aparte de todos mis quehaceres, de mis trabajos como maestra, porque como maestra también me tengo que seguir preparando, pues tenemos cursos. Pero también están los cursos de capacitación que nos da el Instituto de Cultura. Y pues, yo considero que esta es la paga, para mí con eso es más que suficiente, tener buenos cursos, aparte de que me sirven mucho a mí como profesionista, para mi sala, para traerles algo bueno, algo que valga la pena, de calidad a los chicos.

Desde la Sala de Lectura "El Frijolito", ubicada en la Comunidad Santa Ana Chapitiro, en Pátzcuaro, Michoacán, Víctor Manuel de la Cruz Prudencia nos revela: "Tengo Sala de Lectura porque veo la carestía de las comunidades, sobre todo el estudio. No están preparadas, no tienen estudio. La Sala de Lectura me ha dado a conocer tanta gente. Si no hubiera sido por Salas de Lectura y la radiodifusora me hubiera quedado estancado".

Entre los entrevistados existe la certeza de que un buen mediador debe reunir las siguientes características: además de ser un lector frecuente y tener vocación para compartir la vivencia de la lectura, debe tener habilidades para gestionar, facilidad para establecer empatía con los usuarios y capacidad para organizar a las personas. Un buen mediador no teme vivir experiencias nuevas e incluso situaciones imprevisibles. No se paraliza frente a los diversos problemas, como la indiferencia y, en ocasiones, el rechazo de ciertas personas o grupos de la comunidad, o la apatía y el desinterés de los funcionarios públicos. Posee imaginación para encontrar soluciones innovadoras o alternativas que le permitan enriquecer su espacio. El buen mediador es alguien que conoce los problemas de su comunidad y es sensible a las experiencias de vida de sus lectores. Se asume a sí mismo como un agente que incide en el mejoramiento de la vida. Ésta es la perspectiva de los entrevistados. Por ejemplo, Gonzalo García, de Puebla, nos dice en la biblioteca comunitaria que construyó en el zaguán de su casa, junto con su esposa: 
Tenemos registrado en nuestro archivo alrededor de 120 personas, lectores. Es un proyecto que ha dado muchísimos frutos. Los chicos han sobresalido en sus escuelas, no sólo en la primaria y secundaria, sino a nivel de bachillerato. Han avanzado en sus estudios, han participado en concursos y en eventos culturales. Los padres de familia, al ver el crecimiento de sus hijos, se avocan también a participar.

Y Amelia González, de Aguascalientes, apunta:

Yo aquí tengo los registros de la sala, arriba de 20, 30 niños diarios. Ellos van y se registran, y hasta 35 niños hemos tenido en las sesiones a lo largo de todo el trayecto. Tan es así que son consistentes, que sus papás me los están trayendo, poniendo su tiempo, hasta acá. Eso es un logro, que me dieran la confianza de tráemelos hasta acá. Por ejemplo, en la Feria del Libro de Guadalajara, me los llevé para allá.

Por su parte, Martha Martínez Franco, de la Sala de Lectura "El crucero”, en Cancún, Quintana Roo, nos cuenta:

Yo soy del D.F. Yo me he dedicado al comercio. Entonces llegamos aquí y se dio la oportunidad de establecernos. Desde que llegamos, buscamos un lugar donde poder vender y aquí nos quedamos. Poco a poco, empezamos a tener relación con la gente que vende aquí en el parque y nos dimos cuenta de una problemática que estaba muy fuerte, la delincuencia. Entonces nosotros también teníamos la necesidad del rollo cultural. Entonces quisimos promover algo. Primero rescatar el lugar de la delincuencia con la ayuda de todos los vendedores de aquí, del parque. Y después empezamos a promover eventos culturales. A partir de allí conocimos a Guillermo (el enlace estatal) y nos invitó al curso de Salas de Lectura en Bakalart. Asistimos mi esposo y yo. Después del curso regresamos ya con algunos libros que nos habían regalado ahí. También nos dijeron que nos iban a dar un acervo para tener aquí la Sala de Lectura. Y la abrimos aquí. 


\section{¿Dónde se localizan las Salas de Lectura?}

\section{Gráfica 1}

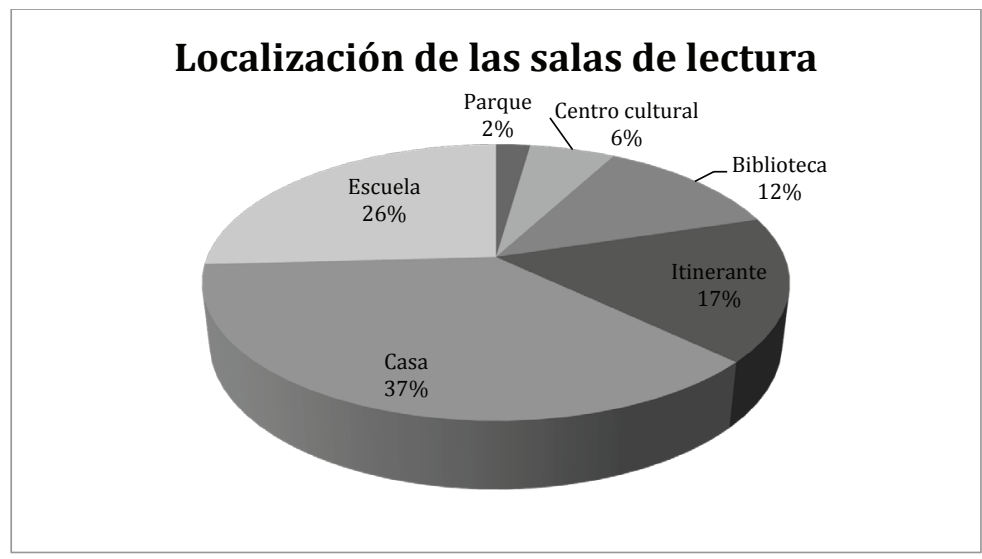

Fuente: Concaculta, PNSL.

La ubicación de las Salas de Lectura que funcionan en el país (gráfica 1) resultó ser un tópico interesante. Constatamos la diversidad y flexibilidad de este programa al identificar que 33\% de las Salas de Lectura se ubican en casas habitación, $23 \%$ en ambientes escolares, $15 \%$ son itinerantes, $11 \%$ en bibliotecas, $5 \%$ en centros culturales, $2 \%$ en parques y $11 \%$ en otros sitios. Esos otros lugares pueden ser centros de readaptación social, albergues y casas hogar para grupos específicos (migrantes, madres solteras, víctimas de violencia familiar, personas de la tercera edad, entre otros), iglesias y capillas de diferentes religiones, mercados y museos. Según los datos recolectados, casi cualquier lugar es susceptible de albergar este proyecto. Tal es el caso de algunos sitios de lectura localizados "a la orilla de un río", "en una sala de masajes", "un billar", "una banqueta", "las escaleras de mi edificio", o una "antigua y abandonada estación de ferrocarril”. Por ejemplo, tenemos el caso de Martha Martínez Franco, de Cancún, Quintana Roo:

La mayoría de los que vienen son de otros lugares, trabajadores, o visitantes. Muchos son buenos lectores. Estamos en un parque y es un lugar donde siempre pasa gente. Los parques son un espacio que la gente quiere ocupar, sentar- 
se, hay árboles. Es un lugar idóneo para hacer algo. Y a la gente le sorprende, me preguntan ¿cómo nació esto? Siento bonito que la gente se sorprenda y muestre simpatía, incluso nos han dejado libros.

Por otra parte, es necesario identificar si el espacio que alberga la Sala de Lectura tiene otros usos (cuadro 4) y, en ese caso, cuáles son éstos. En líneas generales, se observa que la mayoría de las Salas de Lectura $(79.6 \%)$ están ubicadas en lugares donde se realizan actividades no necesariamente relacionadas con el funcionamiento de las salas. Es éste otro punto que confirma la adaptabilidad del programa a las realidades de aquellas comunidades en las que se asienta. Mientras $20 \%$ de los encuestados afirma que el espacio en el que funciona la sala es para su uso exclusivo, las otras salas pueden tener funciones muy variadas de acuerdo con cada entorno.

Cuadro 4. Otros usos del espacio de las Salas de Lectura

\begin{tabular}{|l|c|c|}
\hline \multicolumn{3}{|c|}{$\mathbf{N = 9 5 5}$} \\
\hline & $\mathrm{n}$ & $\%$ \\
\hline Sí & 671 & $79.6 \%$ \\
\hline No & 172 & $20.4 \%$ \\
\hline Total & 843 & $100.0 \%$ \\
\hline
\end{tabular}

Fuente: Conaculta, PNSL.

Cuando se trata de Salas de Lectura ubicadas en casas habitación, los usos adicionales pueden ser aquellos que corresponden al hogar: sala de televisión, estancia, zaguán, garaje y demás. En otros casos, se trata de espacios que repentinamente se adecúan para albergar libros y lectores. Son Salas de Lectura ubicadas en pasillos, escaleras, parques, aceras, salas de espera de hospitales y otros rincones.

\section{Un panorama sobre los usuarios}

En este apartado se abordan aspectos relacionados con los usuarios de las Salas de Lectura, quienes constituyen el elemento central del programa y el principal agente que motiva el trabajo voluntario de los mediadores. Por 
ello, la primera pregunta está relacionada con la cantidad de usuarios. ¿Albergan estas salas un amplio número de usuarios o, por el contrario, su vocación se orienta hacia grupos pequeños y una atención más personalizada?

Tal como se observa en el cuadro 5 , se puede afirmar que la mayoría de estas salas $(86.1 \%)$ atienden a menos de 40 usuarios al mes. Sólo 4.8\% afirma atender mensualmente de 41 a 50 usuarios, y $9.2 \%$ de los encuestados señala que atiende a más de 50 usuarios al mes. Es ésta, pues, una iniciativa de ciudadanos interesados en compartir la experiencia de la lectura con grupos pequeños que representan un reto en términos de continuidad y crecimiento.

Cuadro 5. Usuarios de la sala de lectura al mes

\begin{tabular}{|l|c|c|}
\hline \multicolumn{3}{|c|}{$\mathbf{N = 9 5 5}$} \\
\hline Menos de 10 & 218 & $24.4 \%$ \\
\hline De 11 a 20 & 330 & $36.9 \%$ \\
\hline De 21 a 30 & 143 & $16.0 \%$ \\
\hline De 31 a 40 & 79 & $8.8 \%$ \\
\hline De 41 a 50 & 43 & $4.8 \%$ \\
\hline Más de 50 & 82 & $9.2 \%$ \\
\hline Total & 895 & $100.0 \%$ \\
\hline
\end{tabular}

Fuente: Conaculta, PNSL.

En las Salas de Lectura se atiende a diferentes grupos de edades (cuadro 6). Del total de salas, $38 \%$ prestan servicio principalmente a la población infantil; $34.7 \%$ atiende en su mayoría a usuarios adolescentes y jóvenes; $24.5 \%$ cuenta con un mayor porcentaje de adultos y tan sólo $2.9 \%$ atiende en su mayoría a personas de la tercera edad. Teresa Bazaldúa, responsable de la Sala de Lectura "Pájaros de papel", en Delicias, Chihuahua, nos dice: "Son públicos muy distintos. Ahora que entró lo de los "emos", me llegan jóvenes con esas tendencias. Les gustan los "darketos", les gusta la muerte y esos temas. Entonces ya traigo a un Baudelaire, sé que a los muchachos los va a jalar". 


\section{Cuadro 6. Datos sociodemográficos de los usuarios}

\begin{tabular}{|c|c|c|}
\hline \multicolumn{3}{|c|}{$\mathrm{N}=955$} \\
\hline Grupos de edad & $\mathbf{n}$ & $\%$ \\
\hline Niños & 306 & $38 \%$ \\
\hline Adolescentes y jóvenes & 279 & $34.7 \%$ \\
\hline Adultos & 197 & $24.5 \%$ \\
\hline Tercera edad & 23 & $2.9 \%$ \\
\hline Total & 805 & $100 \%$ \\
\hline \multicolumn{3}{|l|}{ Género } \\
\hline Femenino & 516 & $60.6 \%$ \\
\hline Masculino & 338 & $39.4 \%$ \\
\hline Total & 805 & $100 \%$ \\
\hline \multicolumn{3}{|l|}{ Escolaridad } \\
\hline Preescolar & 64 & $7.0 \%$ \\
\hline Primaria & 364 & $39.6 \%$ \\
\hline Secundaria & 211 & $23.0 \%$ \\
\hline Preparatoria & 192 & $20.9 \%$ \\
\hline Técnica & 22 & $2.4 \%$ \\
\hline Profesional & 67 & $7.3 \%$ \\
\hline Total & 920 & $100 \%$ \\
\hline \multicolumn{3}{|l|}{ Nivel socioeconómico } \\
\hline Alto & 3 & $.3 \%$ \\
\hline Medio alto & 49 & $5.3 \%$ \\
\hline Medio & 374 & $40.7 \%$ \\
\hline Medio bajo & 302 & $32.9 \%$ \\
\hline Bajo & 190 & $20.7 \%$ \\
\hline Total & 918 & $100 \%$ \\
\hline \multicolumn{3}{|l|}{ Ocupación } \\
\hline Estudiante & 635 & $69.2 \%$ \\
\hline Empleado & 70 & $7.6 \%$ \\
\hline Ama de casa & 50 & $5.4 \%$ \\
\hline Profesor & 35 & $3.8 \%$ \\
\hline Otro & 128 & $14 \%$ \\
\hline Total & 918 & $100 \%$ \\
\hline
\end{tabular}

Fuente: Conaculta, PNSL. 
En cuanto a la categoría de género (cuadro 6), $60 \%$ de los mediadores afirma que la mayoría de sus usuarios son mujeres, mientras que $39.4 \%$ asegura que la mayor proporción de sus usuarios son hombres. Es decir, no sólo hay más mediadoras, sino también más usuarias. Marcela Vera Esperanza, de Oaxaca, nos cuenta:

Algunas parejas de las mujeres que asistían a la Sala de Lectura de la Caja de Ahorros lo entendían bien. Pero en el caso de las mujeres mayores, sus maridos se quedaron hechos un lío, otros maridos les llamaban a cada rato para ver a qué horas regresaban a casa. Incluso mujeres jóvenes cuyo esposo les hablaba. Las mujeres nos contaban la larga lista de preguntas de sus maridos: "dónde estuviste, por qué hasta estas horas, con quiénes estuviste, etcétera”. El señor, cuando veía que su esposa llegaba con el libro, como que se calmaba o algo le pasaba. Este marido siempre decía a sus hijos que tenían que estudiar, así que cuando el señor veía que su mujer regresaba con un libro, como que se tranquilizaba. El libro era la posibilidad para que ella pudiera regresar a la Sala de Lectura. Las mujeres cuentan sus experiencias de niñas con la lectura. Una señora que permaneció dos años en la Sala de Lectura, decía que cada vez que se llevaba un libro era el momento en que sentía que podía estar consigo misma, que el tiempo era realmente de ella. Los demás le respetaban su tiempo de lectura. Era una mujer dedicada a servir a los demás. Ella nos reveló muchas cosas. Allí me sentía identificada con ella. Eso me nutre a mí, recibo esas experiencias, eso hace que la motivación continúe.

Con respecto al promedio de escolaridad de los usuarios (véase cuadro 6), $39.6 \%$ de los mediadores señaló que la mayoría de sus usuarios tienen la primaria terminada. Por otra parte, $23 \%$ considera que el promedio de escolaridad de sus usuarios es la secundaria y $20.9 \%$ dice que el promedio de escolaridad de sus usuarios es la preparatoria. Sólo uno de cada 10 mediadores considera que el promedio de los visitantes de su Sala de Lectura cuenta con estudios profesionales. Finalmente, al indagar sobre la ocupación de los usuarios (véase cuadro 6), sobresale que 7 de cada 10 mediadores, afirman que la mayoría de sus usuarios son estudiantes. Desde la Sala de Lectura "Estación Tepa”, en Zempoala, Hidalgo, Carlos Manuel Benítez Mateos señala: 
Aquí la escolaridad está baja, muy baja. Hay casos en que hay niños de $5^{\circ}, 6^{\circ}$ año que no saben leer y, lógico, si no saben leer pues no avanzan. Pero la lectura es fundamental para todo lo que ellos vayan a enfrentar. Entonces, eso me ha motivado mucho, la poca aportación que he dado aquí para ellos es el esfuerzo, lo mejor que puede uno brindar a su pueblo. Esta es otra generación de niños. Necesitábamos literatura para niños, buscamos donaciones y adquisiciones de libros usados. Se ha ido acrecentando el acervo, pero las necesidades siempre van cambiando. Ahorita, en estos días, los jóvenes del Colegio de Bachilleres piden libros de Mario Benedetti. Si veo la oportunidad, voy adquiriendo esos títulos para que no pierdan el interés los jóvenes de venir aquí. Hay veces que me veo en la necesidad de comprar títulos.

Por otra parte, al explorar el promedio del nivel socioeconómico de los usuarios (cuadro 6), según la perspectiva de los mediadores, llama la atención que $40.7 \%$ es de nivel socioeconómico medio, mientras que $32.9 \%$ se ubica en el estrato medio bajo, y $20.7 \%$ corresponde al estrato bajo. Es decir, más de la mitad de las Salas de Lectura del país trabajan con comunidades pobres. Al respecto, Margarita Vázquez Díaz, de Morelia, Michoacán, nos da su testimonio:

El programa Salas de Lectura [...] me ha posibilitado un contacto humanista con la comunidad, un contacto diferente con mi entorno. Compartir la lectura con la gente que ya tiene el gusto y con los que no lo tienen, por ejemplo, las jóvenes del albergue tutelar, que están ahí por delinquir, con una situación económica lamentable, con su escolaridad truncada, con sus papás en el Cereso y sus hermanos en el albergue tutelar también [...] Los libros de historias de princesas, de personajes femeninos les encantaban, como Alicia en el país de las maravillas y Sherezada, les fascinaron. Traté de pasárnosla bien, jugamos, leímos y rompimos los muros del encierro con la imaginación, con las historias.

\section{Valoraciones sobre el impacto de las Salas de Lectura en la comunidad}

Las Salas de Lectura con mejor funcionamiento son aquellas que tienen el apoyo de las instituciones públicas y privadas, pero sobre todo el respaldo de los padres de familia y de los vecinos. Aquí el mediador se convierte en una 
figura ejemplar para la comunidad. Más allá de su mera función de prestador de libros, transmite con su ejemplo sentidos de responsabilidad, compromiso y solidaridad. Entre las experiencias más productivas están aquellas donde los padres, los niños y los jóvenes ayudan en las labores de la sala, como es el caso de la biblioteca comunitaria de la familia de Gonzalo García, en Puebla. Nos dice una usuaria de esta sala:

Iniciamos por nuestros hijos, los llevábamos cada ocho días a la biblioteca pública. Después se hizo difícil, pues teníamos que pagar pasaje. Entonces empezamos a juntarnos acá, en la biblioteca de don Gonzalo. Íbamos de casa en casa, pidiéndoles de favor a los papás que dejaran a sus niños venir a leer. Yo traigo seis o siete niños, pero a veces nos traemos hasta 20 niños al círculo de lectura.

Por su parte, Amelia González, de Aguascalientes, nos da su impresión:

Yo he logrado muchas cosas dentro de la sala, porque básicamente los papás han estado involucrados. A veces los niños me piden libros para sus padres, y yo les digo: "llévate este o aquél". Y luego llevan para su mamá, para su hermana, para su abuelita. Es como ellos mismos se vuelven promotores de lectura.

En Oaxaca, Marcela Vera Esperanza, nos brinda su testimonio:

Entre las socias de la Caja de Ahorros ya hay un hábito por escuchar a las demás. Cómo llegan, cómo han vivido. Cuando leímos algo de Ángeles Mastreta, ese libro que se llama Mujeres de ojos grandes, hubo mujeres de más de 60 años que decidieron abrirse, porque las historias hablaban de las mujeres de antes. Hicieron revelaciones de su vida. La lectura ha hecho posible que ellas me conozcan y que yo las conozca. Ellas son mujeres que tienen muchas cosas en común. Aparentemente con actividades tan diferentes, sin embargo, en el devenir de las sesiones hemos encontrado tantas afinidades con relación a cómo vivimos. Para nosotras no hay tiempo, estamos llenas de chamba, de todo tipo de trabajo. Trabajo de afuera, trabajo de la casa, con la familia, con los compañeros. No tenemos tiempo para nosotras. Teníamos que dar la pelea para estar en las sesiones de lectura, algunas mujeres menos, sobre todo para las que no están casadas. La pelea por el tiempo nos hace estar parejas. Aquí todo mundo propone las lecturas. Mis propuestas son las autoras. Hay autores hombres que 
también me encantan. Hay una novela de Vargas Llosa que queremos leer, se llama Aventuras de la niña mala.

Mericia Ponce Alvarado, quien atiende la Sala de Lectura del Cedes (Centro de Ejecución de Sanciones de Altamira), en Altamira, Tamaulipas, nos relata:

Yo he visto cambios en la forma de actuar, en su comportamiento. En cómo les ha ido transformando su vida, incluso hasta con la familia. A veces la familia me da las gracias y eso es algo que me llena de orgullo. Y ellos me han dicho: "Maestra, gracias porque con usted aprendí a leer. He cambiado mi carácter, con mis compañeros". Yo les meto pláticas de valores, la tolerancia: "Maestra, ¿se acuerda cuando llegué? Pero gracias a su apoyo yo he logrado mejorar mi forma de ser”. Cuando la familia les dice: “¡Cómo has cambiado!” Y ellos les dicen: "Es que estoy en un programa que se llama Salas de Lectura". Para mí eso es mucha más satisfacción que me pagaran un sueldo. Eso me hace sentir orgullosa.

En Guadalupe, Zacatecas, Martha Alicia Mejía Ramírez, mediadora de la Sala de Lectura "Amparo Dávila”, dice:

Tengo niños que empezaron conmigo y que ya van en la preparatoria. No tienen ningún problema de comprensión lectora, ni de calificaciones. Todo eso ha repercutido en lo que son ellos ahora. Una de ellas, Carolina Vargas, acaba de ganar la olimpiada de conocimiento a nivel primaria. Esos pequeños logros son muy difíciles de evaluar. No podemos medir qué tanto lee alguien, si comprende o no comprende. Pero sí se ve el impacto, sobre todo en lo académico. El oír que los niños hablan más fluido, el ver que se recomiendan libros, que se llevan libros y los leen, ver que se están enriqueciendo y que cada día te piden más. Ver los niños que estuvieron viniendo y que crecieron entre los libros de la Sala de Lectura, y que ahora son buenos estudiantes, son sensibles, son creativos.

Sobre los efectos que han tenido las Salas de Lectura en los usuarios, Vivianne Thirion, de la Sala de lectura "El Juglar", en la ciudad de México, afirma: 
¿Transformaciones en las participantes? Lo más importante es que han adquirido valor para hablar y decir lo que piensan, aprenden a pensar, a reflexionar. Se organizan concursos, el premio es un libro, todas escriben y luego votan por el mejor cuento. En la "sesión periódico" se habla de lo de hoy, que se informen de lo que pasa en el mundo. Les pido que lean el periódico al menos una vez a la semana y escojan un artículo, algo que les haya interesado. Las primeras tres en llegar a la sala comentan la nota con las demás. Es importante socializar la lectura. Se trata de circular la palabra, comentar lecturas, crear una atmósfera de libertad de expresión, de respeto, fomentar la participación.

El impacto de este programa en las comunidades, según la apreciación de los mediadores entrevistados, es apenas perceptible. En las comunidades pobres la lectura tiene sentidos más utilitarios o instrumentales. Los lectores buscan constantemente relacionar los contenidos con su experiencia cotidiana. Leer es un acto no necesariamente contemplativo o meramente estético, sino un recurso para entender y actuar con ciertas ventajas ante determinadas situaciones. En estos escenarios, el mito del autor como Creador (con mayúsculas), es casi inexistente. Se sabe muy poco sobre los escritores, las obras, las editoriales y los contextos de la producción literaria: el campo literario y cultural. Se percibe, en cambio, que el libro debe conquistar al lector, y no al revés. Si un libro no les gusta, lo abandonan. No importa que se trate de un autor consagrado. El conocimiento de autores y obras como recurso de poder simbólico en las comunidades pobres es muy débil. De ahí que, aunque se promueva "el placer por la lectura", en estos sectores la lectura pertenece al ámbito del saber escolarizado. Tiene valor en cuanto se mejora el rendimiento escolar de los niños o en cuanto los jóvenes dejan la vagancia o abandonan las malas conductas. De ahí que estos espacios, que a veces desarrollan actividades culturales más amplias, desempeñen en ocasiones un papel fundamental entre los jóvenes de zonas urbanas conflictivas: se convierten en refugios. El mediador se vuelve un consejero que debe ganarse la confianza de los jóvenes, para que éstos participen en las actividades y eventos.

También encontramos Salas de Lectura donde la comunidad ha decidido poner en el centro de sus actividades la defensa de las identidades regionales o locales. Constituyen un proyecto pedagógico, cultural y político de largo plazo. Tal es el caso de la Sala de Lectura "NaruniNabanii", de 
Salina Cruz, Oaxaca (el espíritu de los hombres y mujeres del Istmo de Tehuantepec) o la Sala de Lectura "Carlos Monsiváis" de la ciudad de México. Otros espacios tienen funciones parecidas a las de un centro de desarrollo humano o un centro comunitario, como el Centro Cultural "Nana Chela", en Mexicali, Baja California, encabezado por el maestro y escritor David Monay. Este recinto, situado en uno de los barrios pobres de la ciudad, alberga una biblioteca formal, equipada y atendida por bibliotecarios, voluntarios y prestadores de servicio social. También tiene una sala de cómputo y áreas para exposiciones de artes plásticas. Es un espacio que ofrece no sólo sesiones de lectura y préstamo de libros, también se organizan conferencias, representaciones, ciclos de cine, talleres y cursos diversos. El Centro Cultural "Nana Chela" (que opera como asociación civil) es un ejemplo de organización y eficiencia en uno de los estados que tiene menos Salas de Lectura del país (véase Anexo) y cuya oferta cultural está más comprometida con la cartelera de espectáculos que con la formación de lectores.

\section{El registro fotográfico de las Salas de Lectura}

El análisis visual se realizó con 627 fotografías tomadas por los mediadores en 23 Salas de Lectura que funcionan en los estados de Baja California, Hidalgo, Nuevo León, Oaxaca, Puebla, Veracruz, Jalisco, Nayarit, Colima, Quintana Roo y Tamaulipas, así como el Distrito Federal. Las fotografías se clasificaron en tres categorías: acervo, mediadores de sala y usuarios. De la primera aproximación a las imágenes, resultó una selección de 60 fotografías clasificadas en dos categorías, mediadores y usuarios, que a continuación se analizan. Por motivos de espacio, en este texto sólo se incluyen algunas imágenes.

La fotografía posee entre sus cualidades esenciales la de simular la reproducción idéntica de sus objetos. Parece reproducir fielmente la realidad del objeto fotografiado. Pero ésta, por más realista que pretenda ser, es una construcción tanto como lo es un montaje o una imagen trucada. La fotografía se produce de acuerdo a ciertas reglas sociales y procedimientos técnicos que se aprende a descifrar y que permiten la comprensión convencional de las imágenes.

Esta cualidad propia de la fotografía tiene implicaciones importantes. Por un lado, ofrece un orden al mundo que, de otra forma, resulta desordenado y nos confunde. La fotografía nos indica qué debemos ver, cómo 
deben ser las cosas, las acciones y hasta la forma de mirar la naturaleza que nos rodea. A partir de las fotografías que circulan en nuestro espacio visual, aprendemos a reconocer un "hermoso atardecer", una "buena familia", una escena "bella" de amor o una de violencia. Más de un siglo de fotografías nos han disciplinado en las formas en que vemos las relaciones humanas, los sentimientos de los otros, las ciudades y la naturaleza a nuestro alrededor.

La cualidad de la fotografía de fingir la reproducción idéntica del objeto que retrata produce, además, otro impacto en sus receptores: la sensación de eternizar lo fotografiado. Esta sensación de que la fotografía es el lugar donde se fija indeleblemente la memoria crea la necesidad de solemnizar el instante que se congela en cada foto. De esta manera, se toman fotografías de los días de fiesta, los momentos gozosos, las sonrisas, el campo verde, las casas limpias y compuestas. El fotografiado se acicala para la foto que lo inmortalizará: se alisa el cabello, se lava la cara, se pone las mejores galas y sonríe a la cámara.

Figura 1. Ma. Nieves Moreno Jacobo. Sala de Lectura "La Alegría de Compartir”. El Rincón, Jalisco.

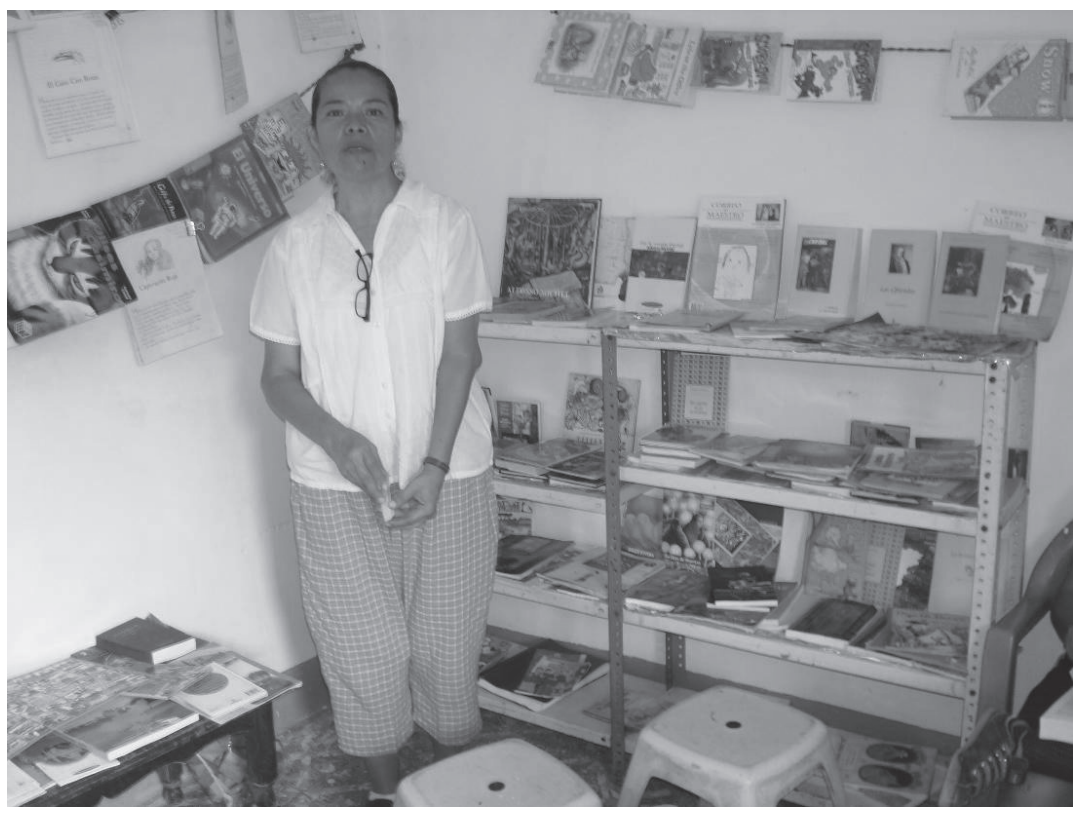


Figura 2. Martha Martínez Franco. Sala de Lectura "El Crucero". Cancún, Quintana Roo.

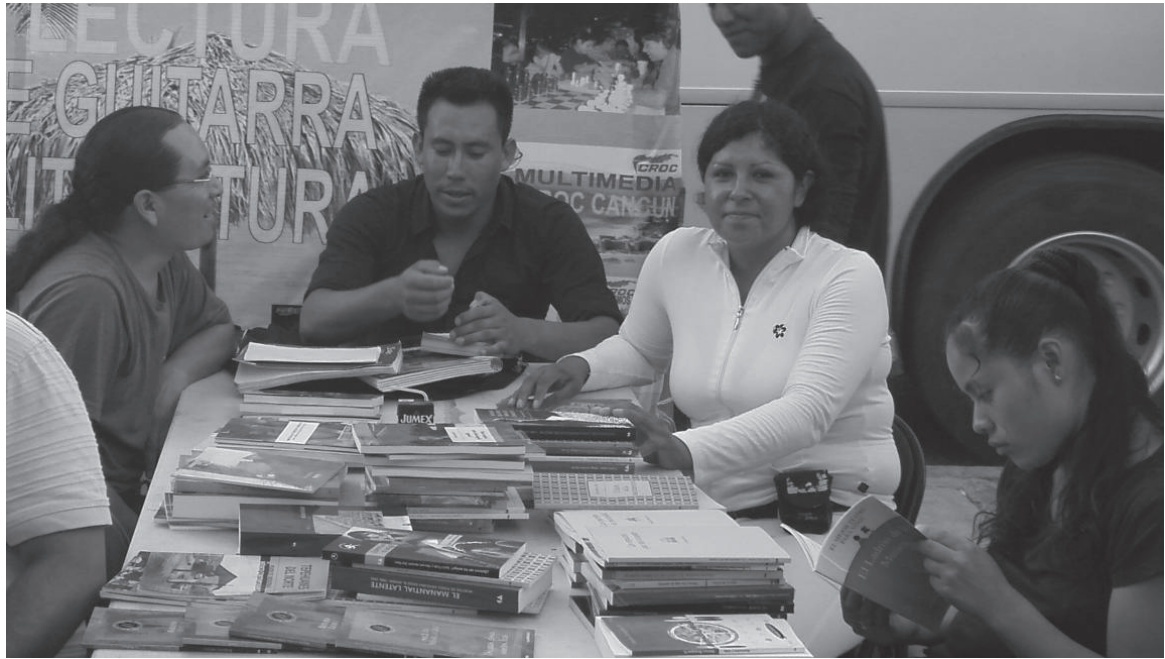

En el conjunto de fotografías analizadas podemos atestiguar que los fotógrafos son aficionados; no son practicantes habituales de la fotografía. Las imágenes nos permiten aproximarnos a lo que los propios mediadores de salas desean mostrarnos sobre su trabajo. En las fotos encontramos las formas elegidas por los mediadores para dar a conocer sus salas, los valores que quieren subrayar, las imágenes que solemnizan y la visión que desean eternizar.

\section{Imágenes de los mediadores de sala}

Es necesario mirar estas fotografías a detalle, lentamente, para descubrir quiénes son los mediadores de sala. Son fotos que, a diferencia de las de los fotógrafos profesionales, requieren tiempo y atención para comprender su sentido: ¿quiénes son estos voluntarios sencillos y generosos que decidieron abrir su espacio para que los demás pudieran acercarse a los libros?

Primero se observa que los mediadores de sala combinan estrechamente su labor social con su vida cotidiana. Abren las puertas de su casa o buscan espacios adecuados para dedicar sus horas no laborales a compartir sus sa- 
beres. Las actividades que deciden realizar son de lo más variadas: leer en el piso, sobre una frazada o en el tianguis; bailar en la cocina, hacer teatro en el jardín, manualidades sobre una tabla en el garaje, entre otros. Cada mediador escoge el rumbo que su sala tomará.

Mientras las fotos profesionales de los publicistas nos muestran la felicidad nerviosa y la del reportero nos enseña la violencia desgarradora, estas fotos nos conmueven porque en ellas reina el equilibrio. Cuando posan frente a sus acervos, los mediadores son los modelos de la meditación y la reflexión. Sin embargo, podemos ver que generalmente los mediadores no son lectores asiduos: su biblioteca consiste en el acervo donado, quizás otros libros escolares y alguna enciclopedia. Pocas son obras clásicas, libros de arte y literatura contemporáneos, libros de actualidad política, científicos, técnicos, revistas o periódicos. Sin embargo, valoran los libros y el poder que éstos otorgan a quien sabe leerlos. ¿Qué más se puede decir sobre los mediadores que no siempre son lectores habituales, que saben muy poco sobre el ámbito de los libros, pero que abren un espacio dedicado a la lectura? ¿Qué se puede decir de estas personas como tipos ejemplares?

Los mediadores de salas son dinamizadores de la cultura. Walter Benjamin encuentra dos tipos de narradores, los que han viajado para contar algo y los que, sedentarios, narran las historias y tradiciones locales. Se trata de tipos fundamentales pues la narración hoy es incomprensible sin la interpenetración de ambos. De la misma manera podemos encontrar dos estirpes de promotores culturales. Aquellos que han viajado, vienen de lejos y traen las novedades que han recogido en su camino. Estos son, por ejemplo, los escritores denotados y los jóvenes poetas, los artistas y los músicos innovadores, los científicos y los técnicos descubridores, los migrantes que regresan para enseñar la cultura de aquellos lugares que han visitado. Los otros promotores culturales, en cambio, son los que se han quedado en la comunidad y conocen sus necesidades. Están familiarizados con las carencias de su entorno. Los mediadores de salas son de este último tipo. Ellos crean algo nuevo cuando en sus Salas de Lectura se renuevan las relaciones de la comunidad o del barrio. En la comunicación entre el mediador y los usuarios renacen vínculos sociales extintos o en peligro de desaparecer; el barrio tiene por fin en las Salas de Lectura un lugar en donde es posible convivir; la comunidad, guiada por el mediador, se reserva un espacio para sí misma acompañado de libros. 
Figura 3. Miguel Ángel Alatorre Álvarez.

Sala de Lectura "El árbol del saber". Colima, Col.

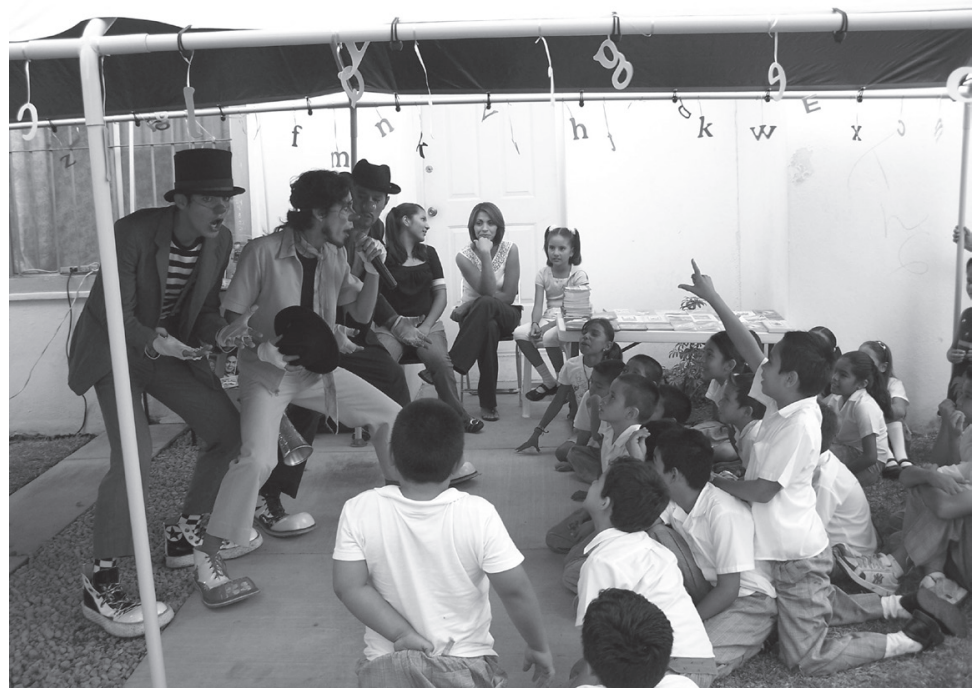

Figura 4. Sala de Lectura "Antorcha". Puebla, Pue. Mediador: Guillermo Durán, "Nemo".

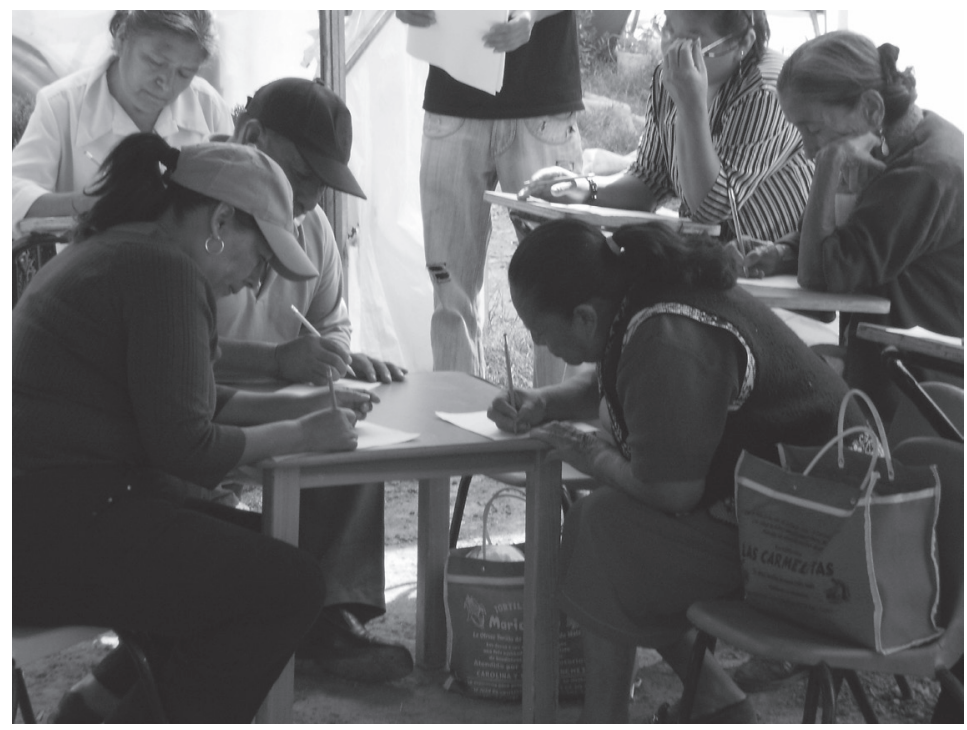




\section{Imágenes de los usuarios}

En las fotografías observamos usuarios muy diversos. Son hombres y mujeres de distintas zonas del país, pero también pertenecen a diferentes clases sociales y grupos de edad. Esta variedad nos permite mirar la diversidad con la que están conformadas las Salas de Lectura. Hay usuarios muy jóvenes, tanto que no pueden aún leer. Otros, aunque también muy pequeños, ya han descubierto el valor social del libro. Hay unos mayores que disfrutan de la lectura o quisieran dominarla. Los hay adultos que comparten con otros adultos sus propias escrituras.

Sin embargo, las actividades que se desarrollan en cada una de las salas están definidas en menor proporción por la edad y más bien por el concepto de cultura y de libro que se tiene en cada contexto social. La lectura en las salas se combina con cuentacuentos y con ejercicios, baile folclórico y danza; o con música y actividades manuales, juegos y debates. Los libros descansan en lugares dispares: repisas, mesas, muebles, cajas, canastas o cajuelas de automóviles. Se clasifican según colecciones, donaciones, público al que van dirigidos, organización numérica o simplemente se ofrecen sin ningún orden para la selección de los usuarios. Se prestan, se leen en la sala, en voz alta o en silencio, los diccionarios se consultan brevemente, se copian recetas de cocina y poemas, se hace la tarea junto con otros niños.

No es obligatorio asistir a las salas y su acceso es gratuito, pero los usuarios se comprometen a su modo con el mediador. Son constantes, cuidan los libros y los regresan. La reciprocidad que se da en el encuentro entre los mediadores y los usuarios es lo que otorga una gran dignidad a las Salas de Lectura.

La cultura se produce a través de un proceso agitado de apropiación y creación de formas (de organización, de materiales, de prácticas, etcétera) que se añaden o sustituyen a las preexistentes. Así se construye la cultura de cada pueblo. Las Salas de Lectura son un espacio dinámico en el cual, alrededor de los libros, se reinventan las formas sociales de convivencia. Los ciudadanos que abren sus espacios para poner una Sala de Lectura realizan informalmente labores de promotores culturales, de bibliotecarios, de cuentacuentos, de coreógrafos, de maestros... La muestra de fotografías realizadas en las Salas de Lectura nos permite asomarnos a una realidad, o mejor dicho, a muchas realidades muy distintas, en las que se nos revela la gran voluntad creativa de la que es capaz la sociedad civil. 


\section{Conclusiones}

Las Salas de Lectura en México se inscriben en escenarios sociales de enorme complejidad. Están determinadas por los desniveles de bienestar, las estructuras profundas de desigualdad, las dinámicas de exclusión y la escasa presencia de las instituciones del estado en diversas regiones del país. Sin embargo, representan también la movilidad de personas y grupos dispuestos a impulsar iniciativas de desarrollo en colaboración con los gobiernos. Existe entre los mediadores la certeza de que el acceso a la lectura mejora las condiciones de vida de la gente. A la vez, encuentran en esta actividad un conjunto de satisfactores y recompensas simbólicas que acrecientan su valor en la comunidad. Un valor que también es político. Precisamente porque no sólo se trata de prestar libros o leer en voz alta, sino de conocer las problemáticas del entorno y de incidir en la vida de los otros.

La mitad de los mediadores están vinculados con el sector educativo. En este sentido, muchas salas se convierten en lugares para enseñar a leer, una tarea que, sin duda, corresponde a la Secretaría de Educación Pública. Si el objetivo del Programa Nacional Salas de Lectura, en contraparte, es formar lectores bajo dinámicas no escolarizadas, es posible que casi la mitad de los mediadores estén desempeñándose al margen de este propósito. No obstante, si reconocemos las condiciones de rezago o bajo rendimiento escolar en muchas regiones y comunidades del país, entonces un conjunto importante de Salas de Lectura están obedeciendo a requerimientos comunitarios específicos, como la atención al desempeño escolar de niños y jóvenes, o la necesidad de revertir escenarios de violencia e inseguridad.

Por otra parte, el estudio reveló un alto grado de compromiso de los mediadores, que además de entregarse a una labor voluntaria, invierten sus propios recursos en una tarea alejada de la utilidad económica. Puede identificarse en este hecho que la capacidad de algunos mediadores para gestionar recursos sugiere un posible espacio alternativo de profesionalización. Recientes enfoques sobre la economía del sector cultural revelan que el fomento a la lectura (y en general la promoción cultural desarrollada en el marco del voluntariado) puede combinarse con proyectos de autogestión que conduzcan a la formación de microempresas culturales.

Aunque más de la mitad de las Salas de Lectura se ubican en casas habitación, escuelas y bibliotecas, uno de los aspectos más atractivos del PNSL con- 
siste en la diversidad de espacios en los que opera, pues dicha flexibilidad permite un mayor acercamiento de la lectura a las comunidades. Sin embargo, casi la mitad de las Salas de Lectura abiertas y activas tienen una antigüedad no mayor de tres años. Y sólo 3\% permanecen vivas desde la fundación del programa. Estos datos representan un escenario inconsistente y al mismo tiempo de gran movilidad. Es un programa que posee un fuerte carácter de emergencia. Se cierran muchas salas, pero se abren otras en contextos dinámicos. De allí que los niveles de institucionalización y de espontaneidad de las Salas de Lectura deban considerarse como un punto de debate central entre usuarios, mediadores y coordinadores adscritos a los estados y la federación. Se identificaron en las entrevistas ciertos puntos de vista sobre el grado de institucionalización que debe el PNSL. Una disyuntiva, sin duda, compleja: ¿más o menos regulación, control y seguimiento por parte de Conaculta? En este sentido, mayor institucionalización significa permanencia y crecimiento de dichos espacios, planificación y seguimiento para la consecución de objetivos y, en términos cotidianos, administración de las energías y de los procesos. Es decir, todo aquello que tiende a formalizar el préstamo de libros: llevar controles, hacer informes, implementar manuales y otros rituales. Bajo este esquema, la desorganización, desaparición o abandono de Salas de Lectura tiende a percibirse, desde la óptica institucional, como retroceso o fracaso del programa.

En contraparte, existe entre los mediadores un consenso sobre las ventajas que tiene el programa al mantener su flexibilidad y modalidad de voluntariado. En este esquema, la iniciativa personal y comunitaria pone en primer plano otras premisas (por supuesto, no ausentes en las instituciones): vocación, compromiso, solidaridad, vitalidad, pasión y confianza. En este esquema, la permanencia y crecimiento de cada sala están sujetos a factores más personales y grupales, donde lo emergente, lo inconsistente y lo desorganizado pueden ser parte constitutiva de la dinámica. Está claro que el PNSL requiere tanto procedimientos de regulación y seguimiento como espacios de libertad y confianza. Creemos que uno de los factores que puede determinar el éxito o fracaso de este programa es el grado de institucionalización o de agencia que se le imprima. Sin procesos de institucionalización, la experiencia ganada se diluye. Donde hay más entusiasmo que conocimiento, más voluntad que método, existe siempre la tendencia a dilapidar recursos humanos, económicos y técnicos. Pero, en el otro extremo, donde 
el control se sitúa en el centro de los procesos, las vocaciones y las energías se apagan y aparece la simulación. El fomento a la lectura supone el desarrollo de estrategias creativas. Toda creación requiere de cierta dosis de caos, de desorden (de allí que muchos talleristas y capacitadores no quieran saber del mundo administrativo), pero al mismo tiempo, no es posible la creatividad sin estructuras, sin cierto nivel de orden. Esta discusión tendrá que ser parte de la agenda del PNSL y deberá de incluir no sólo a los funcionarios y promotores de la lectura, sino a las comunidades involucradas.

Cabe mencionar que los resultados de este estudio no serán del todo fructíferos si no se establece un programa de diagnóstico permanente que posibilite el análisis y la planificación institucional, de cara a los diversos actores involucrados en la promoción de la lectura. Tal como lo señala la Encuesta Nacional de Lectura: "Para comprender con mayor cabalidad las transformaciones de las culturas de la lectura en nuestro país es necesario realizar periódicamente otras encuestas similares y complementarlas con estudios cualitativos" (Conaculta, 2006:184).

Por último, se hicieron evidentes las limitaciones presupuestales y de respaldo técnico con las que trabajan sobre todo los enlaces estatales, quienes en su mayoría no cuentan con personal de apoyo para el seguimiento de las Salas de Lectura de su entidad. En aquellos estados donde los enlaces están comprometidos con el PNSL y tienen el soporte de sus directivos, las Salas de Lectura funcionan muy bien. Es indispensable que las autoridades del Conaculta coloquen el PNSL en las prioridades de los institutos y secretarías de cultura en los estados. La premisa es clara: sin lectores no hay ciudadanos.

\section{Bibliografía}

Bericat, Eduardo (1998), La integración de los métodos cuantitativo y cualitativo en la investigación social, Madrid, Ariel.

Conaculta (2006), Encuesta Nacional de Lectura, México, Consejo Nacional para la Cultura y las Artes.

Corona Berkin, Sarah (2002), Miradas entrevistas. Aproximación a la cultura, comunicación y fotografía huichola, Guadalajara, Universidad de Guadalajara.

Naranjo, Juan (ed.) (2006), Fotografía, antropología y colonialismo (1845-2006), Barcelona, Gustavo Gili.

Salazar Peralta, Ana María (coord.) (1997), Antropología visual, México, unAm. 
Vizcarra, Fernando (2011), "Cultura y desarrollo humano en Baja California. Apuntes para una política cultural", ponencia presentada en el seminario "La cultura como factor de cohesión social”, Tijuana, Centro Cultural Tijuana/Conaculta.

Artículo recibido el 15 de agosto de 2011 Segunda versión recibida el 28 de noviembre de 2011 Artículo aprobado el 10 de diciembre de 2011 


\section{Anexo}

Número de salas de lectura en México, por entidades, 2009

\begin{tabular}{|c|l|c|}
\hline Núm. & \multicolumn{1}{|c|}{ Estado } & Salas activas agosto 2009 \\
\hline 1 & Aguascalientes & 149 \\
\hline 2 & Baja California & 30 \\
\hline 3 & Baja California Sur & 98 \\
\hline
\end{tabular}

\begin{tabular}{|c|l|c|}
\hline 3 & Baja California Sur & 98 \\
\hline 4 & Campeche & 84 \\
\hline 5 & Coahuila & 113 \\
\hline 6 & Colima & 142 \\
\hline
\end{tabular}

\begin{tabular}{|c|l|c|}
\hline 7 & Chiapas & 194 \\
\hline 8 & Chihuahua & 250 \\
\hline 9 & Distrito Federal & NA \\
\hline 10 & Durango & 114 \\
\hline 11 & Estado de México & 91 \\
\hline
\end{tabular}

\begin{tabular}{|c|l|c|}
\hline 11 & Estado de México & 91 \\
\hline 12 & Guanajuato & 347 \\
\hline 13 & Guerrero & 10 \\
\hline 14 & Hidalgo & 32 \\
\hline 15 & Jalisco & 257 \\
\hline
\end{tabular}

\begin{tabular}{|c|l|c|}
\hline 15 & Jalisco & 257 \\
\hline 16 & Michoacán & 167 \\
\hline 17 & Morelos & 50 \\
\hline 18 & Nayarit & 85 \\
\hline 19 & Nuevo León & 131 \\
\hline
\end{tabular}

\begin{tabular}{|c|l|c|}
\hline 19 & Nuevo León & 131 \\
\hline 20 & Oaxaca & 20 \\
\hline 21 & Puebla & 84 \\
\hline 22 & Querétaro & 37 \\
\hline 23 & Quintana Roo & 40 \\
\hline 24 & San Luis Potosí & 188 \\
\hline 25 & Sinaloa & 115 \\
\hline 26 & Sonora & 60 \\
\hline 27 & Tabasco & 70 \\
\hline 28 & Tamaulipas & 60 \\
\hline 29 & Tlaxcala & 51 \\
\hline 30 & Veracruz & 120 \\
\hline 31 & Yucatán & 80 \\
\hline 32 & Zacatecas & 55 \\
\hline & Total & 3324 \\
\hline
\end{tabular}

Fuente: Conaculta, PNSL. 